\title{
Improved characterisation of solitary solid pancreatic tumours using contrast enhanced transabdominal ultrasound
}

\author{
C. F. Dietrich • B. Braden · M. Hocke $\cdot$ M. Ott $\cdot$ A. Ignee
}

Published online: 1 December 2007

(C) Springer-Verlag 2007

\section{Erratum to: J Cancer Res Clin Oncol DOI 10.1007/s00432-007-0326-6}

Owing to a systemic error, some of the data in Table 1 were incorrect. The text referring to Table 1 presents the correct values. The revised version of Table 1 is given here.

The online version of the original article can be found under doi:10.1007/s00432-007-0326-6.

\section{F. Dietrich $(\varangle) \cdot$ A. Ignee}

Medical and Imaging Department,

Caritas-Krankenhaus, Innere Medizin 2,

Caritaskrankenhaus Bad Mergentheim,

Uhlandstr. 7, 97980 Bad Mergentheim, Germany

e-mail: christoph.dietrich@ckbm.de

B. Braden

Medical Department I, University Hospital Frankfurt,

Theodor Stern Kai 7, 60590 Frankfurt am Main, Germany

\section{B. Braden}

Medical Department, John Radcliffe Hospital,

Headley Way, Oxford OX3 9DU, UK

M. Ott

Department of Pathology, Caritas-Krankenhaus,

Uhlandstr. 7, 97980 Bad Mergentheim, Germany

\section{Hocke}

Department of Internal Medicine II,

Friedrich Schiller University Jena,

Erlanger Allee 101, 07740 Jena, Germany
Table 1 Included and excluded patients according to the final diagnosis

\begin{tabular}{lcll}
\hline Final diagnosis & $\begin{array}{l}\text { CEUS } \\
\text { performed }\end{array}$ & $\begin{array}{l}\text { Excluded } \\
\text { from study } \\
\text { evaluation }\end{array}$ & $\begin{array}{l}\text { Included } \\
\text { in study } \\
\text { evaluation }\end{array}$ \\
\hline Pancreatic cancer & 154 & 84 & 70 \\
Neuroendocrinc tumour & 82 & 57 & 25 \\
Serous microcystic adenoma & 16 & 2 & 14 \\
Lymphoma & 8 & 8 & 0 \\
Acinus cell carcinoma & 3 & 3 & 0 \\
Mucinous cystadenoma & 16 & 16 & 0 \\
$\quad$ or cystadenocarcinoma & & 5 & 0 \\
Intraductal papillary & 5 & 5 & 3 \\
$\quad$ mucinous neoplasia & 3 & 0 & \\
Autoimmune pancreatitis & 3 & & \\
\hline
\end{tabular}

Exclusion criteria were: no sign of chronic pancreatitis, cystic lesion $>$ $20 \mathrm{~mm}$, no active hormone production of the tumour, multiple lesions, metastasis, allergic reaction to SonoVue 